\title{
Erratum to: Effect of hot rolling and annealing temperatures on the microstructure and mechanical properties of SP-700 alloy
}

Parnia Parvizian, Maryam Morakabati, and Saeed Sadeghpour

Faculty of Material and Manufacturing Technologies, Malek Ashtar University of Technology, Iran

Erratum to: International Journal of Minerals, Metallurgy and Materials

Volume 27, Number 3, March 2020, Page 374

https://doi.org/10.1007/s12613-019-1922-6

The original version of this article unfortunately contained a mistake. The affiliation of the authors was incorrect. The correct version is given below:

Faculty of Material and Manufacturing Technologies, Malek Ashtar University of Technology, Iran 